DR. NIKKI RAE ADLER (Orcid ID : 0000-0002-7972-9050)

Article type : Original Article

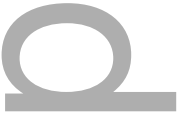

Manuscript Category: Signaling \& Cell biology (SCB)

\title{
Concordance of somatic mutational profile in multiple primary melanomas
}

Nikki R Adler ${ }^{1,2}$, Catriona A McLean ${ }^{1,3}$, Rory Wolfe ${ }^{2}$, John W Kelly ${ }^{1}$, Grant A. McArthur, ${ }^{4,5}$ Andrew Haydon ${ }^{1,6}$, Thien Tra $^{3}$, Nicholas Cummings ${ }^{3}$, Victoria J Mar ${ }^{1,2,7}$

${ }^{1}$ Victorian Melanoma Service, Alfred Hospital, Melbourne, Victoria, Australia

${ }^{2}$ School of Public Health and Preventive Medicine, Monash University, Melbourne, Victoria,

Australia

${ }^{3}$ Department of Anatomical Pathology, Alfred Hospital, Melbourne, Victoria, Australia

${ }^{4}$ Divisions of Research and Cancer Medicine, Peter MacCallum Cancer Centre, East Melbourne,

Victoria, Australia

${ }^{5}$ Sir Peter MacCallum Department of Oncology, University of Melbourne, Melbourne, Victoria,

Australia

${ }^{6}$ Department of Medical Oncology, Alfred Hospital, Melbourne, Victoria, Australia

${ }^{7}$ Skin and Cancer Foundation Inc., Carlton, Victoria, Australia

\section{Corresponding Author:}

Dr Nikki Adler

Victorian Melanoma Service, Alfred Hospital

Melbourne, Victoria, Australia

Phone: (03) 90762000

Email: Nikki.adler@monash.edu

This is the author manuscript accepted for publication and has undergone full peer review but has not been through the copyediting, typesetting, pagination and proofreading process, which may lead to differences between this version and the Version of Record. Please cite this article as doi: $10.1111 / p c m r .12702$

This article is protected by copyright. All rights reserved 


\section{Figures: 1}

Tables: 4

\section{Word count: 4,154}

\section{Summary}

This study aimed to determine the frequency and concordance of BRAF and NRAS mutation in tumours arising in patients with multiple primary melanoma (MPM). Patients with MPM managed at one of three tertiary referral centres in Melbourne, Australia from 2010-2015 were included. Incident and subsequent melanomas underwent mutation testing. Cohen's kappa ( $\kappa)$ coefficient assessed agreement between incident and subsequent primary melanomas for both BRAF and NRAS mutation status (mutant vs. wild-type). Mutation testing of at least two primary tumours from 64 patients was conducted. There was poor agreement for both BRAF and NRAS mutation status between incident and subsequent melanomas ( $\kappa=0.10,95 \% \mathrm{CI}-0.10$ to $0.42 ; \kappa=0.06,95 \% \mathrm{CI}-0.10$ to 0.57 , respectively). In view of the low concordance in $B R A F$ mutation status between incident and subsequent melanomas, mutational analysis of metastatic tissue, rather than of a primary melanoma, in patients with MPM should be used to guide targeted therapy.

\section{Significance}

Knowledge regarding the somatic mutational diversity of tumours in arising in MPM patients remains limited. The low concordance in $B R A F$ and NRAS mutation status between incident and subsequent melanomas highlights the complexity of accurate molecular classification of these patients. In the current era of effective targeted therapies for patients with $B R A F$ mutant metastatic melanoma and recent evidence supporting adjuvant use in stage III disease, it is important to accurately identify patients with activating $B R A F$ mutations who might derive benefit from this therapy. Therefore, in MPM patients, mutational analysis of metastatic tissue should be used to guide targeted therapy.

Key words: melanoma, multiple primary melanoma, $B R A F$ mutation, mutation status

\section{Introduction}

Mutations in the BRAF oncogene occur in approximately $40-50 \%$ of cutaneous melanomas and cause constitutive activation of the mitogen-activated protein kinase (MAPK) signal transduction pathway (Liu et al., 2007; Long et al., 2011; Shain et al., 2015). There is evidence to suggest that BRAF mutations arise early in melanomagenesis and seem to be preserved throughout disease progression (Omholt et al., 2003). BRAF mutant melanomas are associated with distinct clinical and histopathological characteristics, such as younger patient age, superficial spreading subtype, truncal 
location and melanomas arising in areas of intermittent sun exposure compared to areas of cumulative sun exposure (Barbour et al., 2014; Devitt et al., 2011; Ekedahl et al., 2013; Krauthammer et al., 2012; Liu et al., 2007; Maldonado et al., 2003; Mar et al., 2013; Menzies et al., 2012; Poynter et al., 2006; Viros et al., 2008).

The discovery of activating $B R A F$ mutations and the development of targeted therapies have revolutionised the treatment of advanced melanoma for patients with BRAF mutant tumours (Chapman et al., 2011; Flaherty et al., 2012; Luke et al., 2017; Robert et al., 2015). Recent evidence also suggests that adjuvant use of combination therapy with dabrafenib (BRAF inhibitor) plus trametinib (MEK inhibitor) confers a survival advantage for stage III patients with BRAF V600 mutant melanoma (Long et al., 2017). In view of this evidence, which suggests that drugs targeting the MAPK pathway (BRAF inhibitors, $M E K$ inhibitors and combination therapy) enhance survival for patients with BRAF mutant advanced melanoma and that combined BRAF and $M E K$ inhibition improves outcomes for patients with stage III disease, precise molecular classification of patients' disease to guide targeted therapy is of utmost importance. That is, accurately identifying patients with activating $B R A F$ mutations who might derive benefit from drugs targeting the MAPK pathway is crucial.

However, it is important to note that up to $12.7 \%$ of patients with melanoma develop multiple primary melanomas (MPM) (Bradford et al., 2010; DiFronzo et al., 1999; Ferrone et al., 2005; Goggins and Tsao, 2003; Hwa et al., 2012; McMeniman et al., 2010; Murali et al., 2012; Savoia et al., 2012; StamPosthuma et al., 2001; Titus-Ernstoff et al., 2006; Vecchiato et al., 2014). The reported rates are likely a gross underestimation due to limited data capture and follow-up periods of various observational studies. In high risk cohorts, incidence rates for the development of subsequent primary melanomas are even higher (Moloney et al., 2014; Salerni et al., 2012; Watts et al., 2017). The proportion of patients with MPM is also likely to increase due to population increases in life-expectancy, advances in early detection and the rising incidence of melanoma (Jemal et al., 2011; Moore et al., 2015). Patients with dysplastic naevi, a high naevus count and a positive family history of melanoma have an increased risk of developing MPM (De Giorgi et al., 2010; Ferrone et al., 2005; Siskind et al., 2011).

While the phenotypic characteristics of patients with MPM are well-described, there has been limited research investigating the somatic mutation status of tumours arising in patients with MPM (Colombino et al., 2014; Egberts et al., 2016). Similarly, while data on the frequency and clinicopathological correlates of BRAF and NRAS mutation are well-characterised among patients with a single primary melanoma (SPM), information on the somatic mutational diversity of tumours arising in MPM patients remains limited. The aim of this study was to determine the frequency and concordance of $B R A F$ and NRAS mutations in tumours arising in patients with MPM. Information on the somatic mutational diversity of tumours arising in patients with MPM will allow us to better 
understand and more accurately molecularly classify this group of patients. A secondary aim was to describe the clinicopathological characteristics of tumours arising in patients with MPM.

\section{Results}

The Melbourne Melanoma Project (MMP) cohort included 1,638 patients with a histologically confirmed primary cutaneous melanoma diagnosed within 6 months of presentation between 2010 and 2015. Patients were followed up for a median of 4.7 years [interquartile range (IQR) 3.3 - 5.8 years]. There were 1,484 patients diagnosed with a SPM. There were $154(9.4 \%)$ patients with MPM with a total of 406 primary tumours and a mean of 2.6 primary melanomas per patient. Sixty-six patients had a historical primary melanoma at the time of enrolment in the MMP study and 88 patients developed a subsequent primary melanoma during the follow up period. Of the 154 patients with MPM, 98 had two primary melanomas, 37 had three primary melanomas and 19 had four or more primary melanomas (Figure 1).

Among patients with MPM, 38/154 (24.7\%) had a synchronous second primary melanoma detected and 116/154 (75.3\%) developed an asynchronous second primary melanoma. For asynchronous MPM, the median time to the second primary melanoma was 20.7 months (IQR 6.2 - 37.3 months). None of the subsequent primary melanomas developed in patients whilst on systemic therapies. Patients with MPM were older at first melanoma diagnosis compared to patients with a SPM (mean 65.9 vs. 58.9 years, $\mathrm{p}<0.001$ ). Table 1 displays clinical characteristics of the two groups.

\section{Tumour mutation frequencies}

Mutation testing was performed in 221 tumours from patients with MPM and 47 (21.3\%) and 24 (11.7\%) were BRAF and NRAS mutant, respectively. Among the BRAF mutant tumours in the MPM cohort, the most common genotype was V600E (61.7\%), followed by V600K (25.5\%) and less common genotypes $(11.7 \%)$. The vast majority $(91.7 \%)$ of NRAS mutant tumours had an NRAS codon 61 mutation.

$B R A F$ wild-type tumours were significantly more common in the MPM than the SPM cohort $(\mathrm{p}<0.001)$. Indeed, among tumours in 1054 SPM patients with complete mutation testing of their primary tumours, $490(46.5 \%)$ were $B R A F$ mutant, 194 (18.4\%) were NRAS mutant and $370(35.1 \%)$ were $B R A F / N R A S$ wild-type. Among the BRAF mutant tumours in the SPM cohort, the most common genotype was V600E (69.4\%), followed by V600K (24.9\%) and less common genotypes (5.7\%), and 95.4\% of NRAS mutant tumours had an NRAS codon 61 mutation. 


\section{Pathological characteristics of tumours arising in patients with MPM}

Table 2 shows the histopathological characteristics of first and successive melanomas arising in patients with MPM and of melanomas in patients with a SPM. Among patients with MPM, the proportions of melanomas in the thin, intermediate and thick categories were significantly different between first and second (asynchronous) primary melanomas [marginal homogeneity (StuartMaxwell), p=0.016]. Indeed, the first primary melanomas tended to be thicker than the second (asynchronous) primary melanomas (mean Breslow thickness $1.5 \mathrm{~mm} v s .1 .1 \mathrm{~mm}$, respectively; paired sample t-test $95 \% \mathrm{CI}-0.06$ to $0.99, \mathrm{p}=0.04$ ).

Among MPM patients with an incident pigmented melanoma, 132/138 (95.7\%) developed a subsequent pigmented melanoma and 6/138 (4.3\%) developed a subsequent amelanotic/hypomelanotic melanoma. There were six MPM patients with an amelanotic/hypomelanotic incident primary melanoma and all of these patients developed subsequent pigmented melanomas (poor agreement $\kappa=-0.04,95 \%$ CI -0.08 to -0.02 ).

\section{Mutational status concordance in tumours arising in patients with MPM}

Of 64 patients with paired mutation testing of at least two primary melanomas, 43 (67.2\%) patients had concordant $B R A F$ wild-type tumours, three (4.7\%) patients had concordant $B R A F$ mutant tumours and $18(28.1 \%)$ patients had discordant (BRAF mutant/wild-type) mutation status (poor agreement, $\kappa=0.10,95 \% \mathrm{CI}-0.10$ to 0.42 ) (Table 3 ). When stratified by age, among both patients aged less than 60 years and those 60 years or greater, there was poor agreement for BRAF mutation status between incident and subsequent melanomas $(\kappa=0.13,95 \% \mathrm{CI}-0.16$ to $0.70 ; \kappa=0.09,95 \% \mathrm{CI}-0.16$ to 0.48 , respectively). When stratified by sex, agreement for $B R A F$ mutation status between incident and subsequent melanomas was moderate in women $(\kappa=0.4495 \% \mathrm{CI}-0.15$ to 1.00$)$ and poor in men ( $\kappa=-$ $0.03,95 \% \mathrm{CI}-0.19$ to 0.29 ). There was poor agreement for $B R A F$ mutation status among patients with both synchronous and asynchronous primary melanomas when analysed separately $(\kappa=-0.09,95 \% \mathrm{CI}$ 0.31 to $0.00 ; \kappa=0.11,95 \% \mathrm{CI}-0.13$ to 0.42 , respectively). There was also poor agreement for NRAS mutation status between incident and subsequent melanomas ( $\kappa=0.06,95 \% \mathrm{CI}-0.10$ to 0.57 ) (Table 4 ).

\section{Discussion}

This study analysed the somatic mutation profile and concordance among matched incident and subsequent primary melanomas arising in patients with MPM. The findings of this study show that there is poor concordance for $B R A F$ and NRAS mutation status between first and successive primary melanomas. This discordance highlights the complexity of accurate molecular classification of this 
group of patients and provides greater insight into the somatic mutational profile of patients with MPM.

In patients with metastatic disease, accurately identifying the presence of an activating BRAF mutation is critical to inform clinical management. Indeed, the introduction of both single-agent and combination targeted therapies have led to significant improvements in overall survival and progression-free survival in patients with $B R A F$ mutant advanced melanoma (Chapman et al., 2011; Flaherty et al., 2012; Robert et al., 2015; Sosman et al., 2012). More recently, adjuvant combination targeted therapy has shown a survival advantage for patients with $B R A F$ mutant stage III disease (Long et al., 2017). Therefore, BRAF mutation testing has important treatment implications and will likely occur at an earlier stage to guide clinical decision making.

However, prior to the administration of targeted therapies, molecular testing of a patient's primary tumour or of a metastatic tumour deposit is required to detect the presence of an actionable BRAF V600 mutation. There are currently no clear guidelines regarding which melanoma specimen (i.e. primary tumour, locoregional metastatic deposit or distant metastatic deposit) should be used for $B R A F$ mutation testing. For patients with metastatic disease, common practice is to perform mutational analysis on the most readily available and/or recently obtained tumour sample, with an adequate quantity of viable tumours cells and minimal admixture of non-tumour cells (Menzies et al., 2014). In the absence of clear guidelines, clinical decision making regarding which tumour specimen to be tested may become particularly complicated in patients with MPM.

Indeed, in our MMP cohort, 9.4\% of melanoma patients were diagnosed with MPM. This is consistent with the existing literature, which indicates that up to $12.7 \%$ of patients with melanoma will develop synchronous or asynchronous MPM (Bradford et al., 2010; DiFronzo et al., 1999; Ferrone et al., 2005; Goggins and Tsao, 2003; Hwa et al., 2012; McMeniman et al., 2010; Murali et al., 2012; Savoia et al., 2012; Stam-Posthuma et al., 2001; Titus-Ernstoff et al., 2006; Vecchiato et al., 2014). Indeed, when there is discordance in the mutation status of incident and subsequent primary melanomas in patients with metastatic melanoma, treatment decisions regarding targeted therapy become complex, in the absence of mutation testing of a metastatic deposit.

A recent German retrospective cohort study assessed the mutation status of BRAF and NRAS oncogenes and TERT-promoter in 96 MPM patients with 237 primary melanomas (Egberts et al., 2016). These investigators demonstrated that mutation patterns in BRAF, NRAS and TERT were concordant between first and subsequent primary tumours in $23.9 \%$ of patients and discordant in $61.4 \%$ of patients, where concordance referred to an identical genotype in all three genes and all melanomas (Egberts et al., 2016). An Italian study assessed the frequency and distribution of alterations in BRAF, cKIT and CyclinD1 in 112 patients with MPM and also showed that there was low concordance in somatic mutation patterns among paired multiple primary tumours with $32.8 \%$ 
having a discrepant BRAF mutation pattern between first and subsequent primary tumours (Colombino et al., 2014). Consistent with Egberts et al.'s study (Egberts et al., 2016) and ours, concordance in BRAF mutation was similar among patients with synchronous and asynchronous multiple primary melanomas (Colombino et al., 2014). Taken together, these findings and ours demonstrate that tumours arising in patients with MPM often have heterogeneous somatic mutational profiles.

To the authors' knowledge, the aforementioned two studies and ours are the only studies to have specifically explored $B R A F$ mutation status concordance of tumours arising in patients with MPM. As well as providing descriptive statistics in the form of tumour mutation frequencies and the percentages of concordant mutation patterns, our study used Cohen's $\kappa$ coefficient to assess inter-sample agreement for $B R A F$ and NRAS mutation status between first and successive primary melanomas. Unlike our study, this method of statistical testing was not used in Egberts et al.'s (Egberts et al., 2016) and Colombino et al.'s (Colombino et al., 2014) studies. This method represents a considerable improvement over raw percentage calculations as the $\kappa$ statistic provides a quantitative measure of agreement that has been adjusted for the degree of agreement expected solely on the basis of chance (Viera and Garrett, 2005). An additional methodological strength of our study is that we have presented the $\kappa$ coefficients with bias-corrected and accelerated 95\%CIs, which automatically adjusts for bias and skewness in the bootstrap distribution (Kang et al., 2013).

Of note, several studies have shown good inter-tumoural agreement in $B R A F$ mutation status between primary and metastatic tumour samples from patients with a SPM (Boursault et al., 2013; Menzies et al., 2014; Nardin et al., 2015; Riveiro-Falkenbach et al., 2015; Satzger et al., 2015). Nonetheless, several other studies have demonstrated varying rates of intra-patient heterogeneity with respect to $B R A F$ mutation status in primary and metastatic tumour samples (Bradish et al., 2015; Colombino et al., 2012; Heinzerling et al., 2013a; Saint-Jean et al., 2014). While this area of research remains somewhat controversial, the reported inter-tumoural heterogeneity for $B R A F$ mutation status between primary and metastatic tissue adds further weight to our recommendation to test for the presence of a $B R A F$ mutation in metastatic tissue rather than a primary melanoma in patients with MPM.

Furthermore, the overall frequency of BRAF mutation (21.3\%) in our cohort of patients with MPM and in Egberts et al.'s German cohort (35.4\%) (Egberts et al., 2016) appear to be considerably lower than that reported in studies of patients with a SPM (Greaves et al., 2013; Heinzerling et al., 2013b; Liu et al., 2007; Long et al., 2011; Menzies et al., 2012) and indeed, in our cohort of SPM patients (46.5\%). There are multiple possible reasons that could account for this, one of which is that BRAF mutation is well-known to be associated with younger patient age (Liu et al., 2007; Long et al., 2011; Menzies et al., 2012), whereas patients with MPM tend to be older at first melanoma diagnosis, as shown in our study and others (Bower et al., 2010; Hwa et al., 2012; McCaul et al., 2008; Moore et al., 2015). Indeed, Long et al.'s prospective cohort study showed a statistically significant association 
between $B R A F$ mutation and a single or occult primary melanoma (OR 4.8, 95\%CI 1.1-21.1, $\mathrm{p}=0.037$ ) (Long et al., 2011). These authors therefore concluded that there is likely to be a relationship between $B R A F$ wild-type melanoma and a history of multiple primary melanomas (Long et al., 2011).

Moreover, in our study, $24.7 \%$ of MPM patients had synchronous primary melanomas, whereas $75.3 \%$ developed asynchronous primary melanomas. This is similar to the existing literature, which suggests that $15-40 \%$ of MPM develop as synchronous lesions, while the remainder develop as asynchronous lesions (De Giorgi et al., 2010; DiFronzo et al., 2001; Goggins and Tsao, 2003; Savoia et al., 2012; Stam-Posthuma et al., 2001; Vecchiato et al., 2014). The median time to the second (asynchronous) primary melanoma was 20.7 months in our study. This is similarly consistent with the existing literature, which suggests that the relative risk of developing a subsequent primary melanoma is highest in the first year following diagnosis of the incident primary melanoma (Goggins and Tsao, 2003; Hwa et al., 2012; Moore et al., 2015; Murali et al., 2012; Savoia et al., 2012; Youlden et al., 2014). A population-based cohort study from Queensland, Australia recently showed that the median time between diagnosis of first and second primary melanoma was 3.0 years, after excluding melanomas diagnosed on the same day (Youlden et al., 2017). This underscores the importance of intensive clinical surveillance in the first few years following a primary melanoma diagnosis in addition to lifelong follow up as the cumulative incidence rates will inevitably increase with time.

An interesting finding from our study was that there was poor agreement ( $B C a \kappa=-0.04)$ in pigmentation status (pigmented vs. amelanotic/hypomelanotic) between matched incident and subsequent primary melanomas. However, we had a very low rate of amelanosis/hypomelanosis (3.0\%) in our cohort of patients with MPM, which may have underestimated the $\kappa$ coefficient and level of agreement. A recent international, population-based cohort study showed that patients with incident primary amelanotic melanomas were more likely to have had a prior primary amelanotic melanoma than those with an incident primary pigmented melanoma (OR, 4.62; 95\%CI, 1.25-14.13) (Vernali et al., 2017). These results suggest that clinicians should maintain an increased index of suspicious when assessing amelanotic/hypomelanotic lesions in the follow up of patients with a history of amelanotic/hypomelanotic melanoma. The relationship between tumour mutation status and amelanosis/hypomelanosis represents an important area for future research.

In our study, the percentage of nodular melanoma decreased with successive melanomas $(21.5 \%, 10.9 \%$ and $5.8 \%$ in first, second and third primary melanomas, respectively). Previous studies have also reported that the nodular melanoma subtype is less common in subsequent primary melanomas compared to incident primary melanomas (Buljan et al., 2010; Moore et al., 2015; Savoia et al., 2012). Correspondingly, lentigo maligna subtype has been shown to be more common in subsequent primary melanomas (Buljan et al., 2010; Murali et al., 2012). Our study confirms this finding as lentigo maligna subtype occurred in $15.6 \%, 26.5 \%$ and $28.9 \%$ of first, second and third primary melanomas, respectively. Lentigo maligna subtype has also been shown to be over-represented in both incident 
and subsequent melanomas in patients with MPM (Moore et al., 2015; Murali et al., 2012), which was also in keeping with our findings. This supports a heightened role for sun exposure as part of the pathogenesis of melanomas arising in patients with MPM.

Furthermore, the second primary melanomas in our study were significantly thinner on average than the first primary melanomas. Youlden et al.'s population-based cohort study showed no significant differences in thickness between first and second primary melanomas in a cohort of patients from Queensland, Australia (Youlden et al., 2016). Nonetheless, the existing literature overwhelmingly indicates that subsequent primary melanomas are more likely to be thinner than incident primary melanomas (Bradford et al., 2010; De Giorgi et al., 2010; DiFronzo et al., 2001; Ferrone et al., 2005; Moore et al., 2015; Moscarella et al., 2013; Murali et al., 2012; Savoia et al., 2012; Stam-Posthuma et al., 2001; Vecchiato et al., 2014). This may be explained by early detection as a result of improved clinical surveillance (De Giorgi et al., 2010; DiFronzo et al., 2001; Murali et al., 2012). In support of the early detection hypothesis, a retrospective study demonstrated that patients with MPM who adhered to regular follow-up had significantly thinner subsequent primary melanomas compared to those who did not (0.36 vs. $1.22 \mathrm{~mm}, \mathrm{p}=0.02$ ) (De Giorgi et al., 2010). In further support of the early detection hypothesis, a case-control study demonstrated that subsequent primary melanomas that were diagnosed after three years from the incident primary melanoma, which corresponded to a time when follow-up had become less intense, were thicker than those diagnosed within the first three years after diagnosis (Murali et al., 2012). This highlights the importance of regular skin surveillance to detect subsequent primary melanomas at an early clinical stage.

Strengths of our study included the multicentre and prospective nature of the study design. In addition, the MMP database includes high-quality longitudinal follow up data in order to capture the diagnosis of subsequent primary melanomas, which compares favourably to other databases. It also contains multiple tumour-related variables, providing a histologically well-characterised dataset.

A limitation of our study is that we could not present data on participants' naevus density as this variable was inconsistently recorded across the institutions. A further limitation is that of possible referral bias as our study was conducted at three tertiary referral centres in Melbourne, Australia, and therefore, patients with higher risk melanomas may have been disproportionately represented. Another limitation is that the median follow-up time was 4.7 years; thus, our study would not have captured patients who might have later developed a subsequent primary melanoma. However, in view of the fact that the median time to a second (asynchronous) primary melanoma was 20.7 months (IQR 6.2 - 37.3 months), our study likely captured a substantial majority of second primary melanomas. A further limitation was the lack of availability of all tumour samples for molecular testing as some of the external laboratories were unable to send specimens for prospective molecular testing. This raises the possibility of ascertainment bias. However, there were no significant differences in important clinicopathological characteristics (i.e. age, sex, Breslow thickness, mitotic rate, ulceration) between 
those that were sent and those that were not sent for prospective mutational testing (all $p$ values $\geq 0.5$ ). A further limitation is that we did not test for additional somatic mutations; this might represent an area for future research. Nonetheless, we tested for the important driver oncogenes, BRAF and NRAS. $B R A F$ is currently the most actionable mutation in melanoma and BRAF mutation status directly informs therapeutic decisions consideration of targeted therapy (i.e. drugs targeting the MAPK pathway).

In conclusion, our study contributes to the existing literature by providing additional information on the frequency and concordance of BRAF and NRAS mutation status in patients with synchronous and asynchronous MPM. In the current era of effective targeted therapies for patients with BRAF mutant metastatic melanoma and recent evidence supporting adjuvant use in stage III disease, it is important, now more than ever, to precisely identify patients with activating $B R A F$ mutations who might derive benefit from this therapy. The observed low concordance in somatic mutation status between incident and subsequent primary melanomas underscores the complexity of accurate molecular classification of these patients. In patients with MPM who develop metastatic disease, it is not always possible to accurately predict which primary tumour was responsible for the metastatic disease. In view of the low concordance in BRAF mutation status, mutational analysis of metastatic tissue, rather than of a primary melanoma, should be used to guide targeted therapy in patients with MPM.

\section{Methods \\ Study participants and data collection}

This was a prospective cohort study of participants in the Melbourne Melanoma Project (MMP). Patients referred to one of three tertiary referral centres in Melbourne, Australia (Victorian Melanoma Service at the Alfred Hospital, Peter MacCallum Cancer Centre and the Olivia Newton-John Cancer Research Institute at the Austin Hospital) with a histologically confirmed primary cutaneous melanoma were eligible for enrolment in the MMP. Patients were enrolled within 6 months of presentation to the abovementioned institutions between 2010 and 2015. Institutional ethics approval was obtained from the contributing sites (project number 07/38). All patients had provided written informed consent prior to inclusion in the study. Patients with uveal melanoma, mucosal melanoma or melanoma of unknown primary site were excluded.

MMP participants were included in this analysis if they were diagnosed with MPMs, which was defined as multiple primary melanomas (invasive or in situ) that originated in independent primary sites and did not represent cutaneous metastases. MPM was categorised as synchronous or asynchronous. Synchronicity has been defined in different ways in melanoma research; however, we have used the most widely accepted definition, which describes the occurrence of a subsequent 
primary melanoma within one month of the diagnosis of the incident primary melanoma.(Manganoni et al., 2007; Savoia et al., 2012; Schuurman et al., 2016; Siskind et al., 2011)

Clinical, pathological and molecular characteristics were prospectively recorded. The clinical variables that were recorded by the treating doctor at the patients' initial presentation included: age, sex, phenotypic markers (eye colour, hair colour and skin phototype), personal history of nonmelanoma skin cancer and family history of melanoma.

The tumour characteristics that were collected in the MMP database for each melanoma included: date of diagnosis, anatomical location of the primary tumour, Breslow thickness (mm), Clark level, histologic subtype, mitotic rate $\left(n / \mathrm{mm}^{2}\right)$, ulceration, tumour infiltrating lymphocytes, regression and amelanosis/hypomelanosis. The anatomical location of the primary tumour was classified as upper extremity, lower extremity, head and neck region, or trunk. Clinical amelanosis/hypomelanosis, as assessed by the doctor, patient or family, represented melanomas with little or no pigment on visual inspection (Pizzichetta et al., 2004).

\section{Mutation testing}

Among all patients enrolled in the MMP database, $71 \%$ of patients had BRAF and NRAS mutation testing of one of their primary melanomas at enrolment. This mutation testing was performed at the Department of Anatomical Pathology, Alfred Hospital, Melbourne, Australia or the Department of Diagnostic Molecular Pathology, Peter MacCallum Cancer Centre, Melbourne, Australia. Hematoxylin and eosin-stained sections of formalin-fixed, paraffin-embedded tissue were reviewed by a pathologist, followed by macrodissection to ensure the percentage of tumour cells was enriched to at least $30 \%$. DNA was then extracted from each sample and checked for adequate concentration. Matrix assisted laser desorption ionisation time-of-flight (MALDI-TOF) mass spectrometry was used for mutational analyses. DNA quality was evaluated via Eppendorf spectrophotometer. The sample was checked for multiple known mutations in BRAF (exon 11 and 15), NRAS (exon 2, 3 and 4) and KIT (exon 11,13 and 17) using Sequenom (Agena) Mass ARRAY OncoFocus panel (Version 3). The vast majority of samples were tested by the method described above. A minority of samples were tested at Peter MacCallum Cancer Centre with next generation sequencing (Illumina MiSeq) or high resolution melting (HRM) analysis following macrodissection of the paraffin-embedded tumour specimens, as previously described (Devitt et al., 2011; Wong et al., 2014).

In order to assess agreement between first and successive primary melanomas in patients with MPM, the investigators subsequently analysed the mutational profile of the additional (successive or historical) melanomas that had not been analysed at enrolment, or of both primary melanomas in patient who did not have mutation testing of one of their melanomas at enrolment. To this end, the investigators requested that tissue from each of the patients' additional primary melanomas be sent 
from the external laboratories to the Department of Anatomical Pathology, The Alfred Hospital, Melbourne, Australia, for prospective mutation testing. Mutation testing of at least two primary melanomas was only able to be conducted for 64/154 (42\%) patients with MPM in our cohort. Several laboratories did not respond to the authors' multiple requests and a few laboratories were unable to retrieve the archival tissue, particularly for more historic specimens.

\section{Statistical analyses}

All statistical analyses were performed using Stata version 14.2 (StataCorp LP, College Station, Texas, USA) statistical software. Baseline descriptive statistics included proportions, mean or median, as appropriate by data distribution. Breslow thickness $(<1 \mathrm{~mm}, 1.00-4.00 \mathrm{~mm},>4.01 \mathrm{~mm})$ and mitotic rate $\left(<5 / \mathrm{mm}^{2}, 5-9 / \mathrm{mm}^{2}\right.$ and $\left.\geq 10 / \mathrm{mm}^{2}\right)$ were analysed as ordinal variables and age was dichotomised as less than or greater than 60 years. Ulceration, tumour infiltrating lymphocytes, regression and amelanosis/hypomelanosis were analysed as binary variables. Tumour histologic subtype was analysed as a nominal variable (superficial spreading melanoma (SSM), nodular melanoma (NM), lentigo maligna melanoma (LMM) and 'other'). 'Other' represented acral lentiginous melanoma, desmoplastic melanoma and other less common tumour subtypes including naevoid, balloon cell, spindle cell and Spitzoid melanoma. BRAF and NRAS mutation status were both classified as mutant or wild-type. $\chi^{2}$ tests were used to compare clinical categorical covariates between patients with a SPM in the MMP cohort and those with MPM.

For patients with MPM, Cohen's kappa ( $\kappa)$ coefficient was used to assess agreement between paired incident and subsequent primary melanomas for $B R A F$ and $N R A S$ mutation status (mutant vs. wildtype). Discordance for $B R A F$ corresponded to the presence of a $B R A F$ mutation in one primary melanoma and a $B R A F$ wild-type status in another primary melanoma from the same patient. Agreement for $B R A F$ mutation status among patients with both synchronous and asynchronous primary melanomas were also analysed separately. A $\kappa$ value of 0 indicates agreement equivalent to that expected by chance. According to Landis and Koch, the following $\kappa$ values were used for interpretation: poor-to-fair $(\leq 0.4)$, moderate (0.41-0.60), substantial (0.61-0.80) and almost perfect agreement (0.81-1.00) (Landis and Koch, 1977). Bias-corrected and accelerated $\left(B C_{a}\right)$ confidence intervals $(95 \% \mathrm{CI})$ for Cohen's $\kappa$ coefficient were constructed by bootstrapping, using 1,000 bootstrap replicates (Kang et al., 2013). The $\kappa$ coefficient was also used to assess agreement for pigmentation status (amelanotic/hypomelanotic vs. pigmented) between incident and subsequent primary melanomas. The Stuart-Maxwell test for marginal homogeneity and the paired sample t-test were used to examine Breslow thickness among incident and subsequent primary melanomas, analyzed as a categorical and numerical variable, respectively. $P$ values of less than 0.05 were considered statistically significant. 
Acknowledgements: The authors would like to thank Ms Sonia Louise Mailer for her work as the Melbourne Melanoma Project database manager.

Funding sources: NRA is supported by a Research Training Program (RTP) stipend scholarship, Monash University; this research project was supported by the Victorian Government through the Victorian Cancer Agency Translational Research Program; GAM is supported by the NHMRC and The Lorenzo Galli Chair in Melanoma and Skin Cancer from the University of Melbourne.

Conflicts of interest: none disclosed.

\section{References}

Barbour, A. P., Tang, Y. H., Armour, N., Dutton-Regester, K., Krause, L., Loffler, K. A., Lambie, D., Burmeister, B., Thomas, J., Smithers, B. M., et al. (2014). BRAF mutation status is an independent prognostic factor for resected stage IIIB and IIIC melanoma: implications for melanoma staging and adjuvant therapy. European Journal of Cancer 50(15), 2668-76.

Boursault, L., Haddad, V., Vergier, B., Cappellen, D., Verdon, S., Bellocq, J.-P., Jouary, T., and Merlio, J.-P. (2013). Tumor homogeneity between primary and metastatic sites for BRAF status in metastatic melanoma determined by immunohistochemical and molecular testing. Plos One 8(8), e70826.

Bower, M. R., Scoggins, C. R., Martin, R. C., 2nd, Mays, M. P., Edwards, M. J., Reintgen, D. S., Ross, M.I., Urist, M. M., Noyes, R. D., Sussman, J. J., et al. (2010). Second primary melanomas: incidence and outcome. The American Surgeon 76(7), 675-81.

Bradford, P. T., Freedman, D. M., Goldstein, A. M., and Tucker, M. A. (2010). Increased risk of second primary cancers after a diagnosis of melanoma. Archives of Dermatology 146(3), 26572.

Bradish, J. R., Richey, J. D., Post, K. M., Meehan, K., Sen, J. D., Malek, A. J., Katona, T. M., Warren, S., Logan, T. F., Fecher, L. A., et al. (2015). Discordancy in BRAF mutations among primary and metastatic melanoma lesions: clinical implications for targeted therapy. Modern Pathology 28(4), 480-6.

Buljan, M., Situm, M., Bolanca, Z., Zivkovic, M. V., and Mihic, L. L. (2010). Multiple primary melanoma: epidemiological and prognostic implications; analysis of 36 cases. Collegium Antropologicum 34, Suppl 2, 131-4. 
Chapman , P. B., Hauschild , A., Robert , C., Haanen , J. B., Ascierto , P., Larkin , J., Dummer , R., Garbe , C., Testori , A., Maio , M., et al. (2011). Improved survival with Vemurafenib in Melanoma with BRAF V600E Mutation. New England Journal of Medicine 364, 2507-2516.

Colombino, M., Capone, M., Lissia, A., Cossu, A., Rubino, C., De Giorgi, V., Massi, D., Fonsatti, E., Staibano, S., Nappi, O., et al. (2012). BRAF/NRAS mutation frequencies among primary tumors and metastases in patients with melanoma. Journal of Clinical Oncology 30(20), $2522-9$.

Colombino, M., Sini, M., Lissia, A., De Giorgi, V., Stanganelli, I., Ayala, F., Massi, D., Rubino, C., Manca, A., Paliogiannis, P., et al. (2014). Discrepant alterations in main candidate genes among multiple primary melanomas. Journal of Translational Medicine 12, 117-117.

De Giorgi, V., Rossari, S., Papi, F., Gori, A., Alfaioli, B., Grazzini, M., Crocetti, E., Verdelli, A., Foo, C. W., and Lotti, T. (2010). Multiple primary melanoma: the impact of atypical naevi and follow up. British Journal of Dermatology 163(6), 1319-1322.

Devitt, B., Liu, W., Salemi, R., Wolfe, R., Kelly, J., Tzen, C. Y., Dobrovic, A., and Mcarthur, G. (2011). Clinical outcome and pathological features associated with NRAS mutation in cutaneous melanoma. Pigment Cell \& Melanoma Research 24(4), 666-72.

Difronzo, L. A., Wanek, L. A., Elashoff, R., and Morton, D. L. (1999). Increased incidence of second primary melanoma in patients with a previous cutaneous melanoma. Annals of Surgical Oncology 6(7), 705-11.

Difronzo, L. A., Wanek, L. A., and Morton, D. L. (2001). Earlier diagnosis of second primary melanoma confirms the benefits of patient education and routine postoperative follow-up. Cancer 91(8), 1520-4.

Egberts, F., Bohne, A. S., Kruger, S., Hedderich, J., Rompel, R., Haag, J., Rocken, C., and Hauschild, A. (2016). Varying Mutational Alterations in Multiple Primary Melanomas. The Journal of molecular diagnostics. Journal of Molecular Diagnostics 18(1), 75-83.

Ekedahl, H., Cirenajwis, H., Harbst, K., Carneiro, A., Nielsen, K., Olsson, H., Lundgren, L., Ingvar, C., and Jonsson, G. (2013). The clinical significance of BRAF and NRAS mutations in a clinic-based metastatic melanoma cohort. British Journal of Dermatology 169(5), 1049-55.

Ferrone, C. R., Ben Porat, L., Panageas, K. S., Berwick, M., Halpern, A. C., Patel, A., and Coit, D. G. (2005). Clinicopathological features of and risk factors for multiple primary melanomas. JAMA 294(13), 1647-54.

Flaherty, K. T., Infante, J. R., Daud, A., Gonzalez, R., Kefford, R. F., Sosman, J., Hamid, O., Schuchter, L., Cebon, J., Ibrahim, N., et al. (2012). Combined BRAF and MEK inhibition in melanoma with BRAF V600 mutations. The New England Journal of Medicine 367, 1694703.

Goggins, W. B., and Tsao, H. (2003). A population-based analysis of risk factors for a second primary cutaneous melanoma among melanoma survivors. Cancer 97(3), 639-43. 
Greaves, W. O., Verma, S., Patel, K. P., Davies, M. A., Barkoh, B. A., Galbincea, J. M., Yao, H., Lazar, A. J., Aldape, K. D., Medeiros, L. J., et al. (2013). Frequency and spectrum of BRAF mutations in a retrospective, single-institution study of 1112 cases of melanoma. Journal of Molecular Diagnostics 15(2), 220-6.

Heinzerling, L., Baiter, M., Kuhnapfel, S., Schuler, G., Keikavoussi, P., Agaimy, A., Kiesewetter, F., Hartmann, A., and Schneider-Stock, R. (2013a). Mutation landscape in melanoma patients clinical implications of heterogeneity of BRAF mutations. British Journal of Cancer 109(11), $2833-41$.

Heinzerling,L., Kuhnapfel, S., Meckbach, D., Baiter, M., Kaempgen, E., Keikavoussi, P., Schuler, G., Agaimy, A., Bauer, J., Hartmann, A., et al. (2013b). Rare BRAF mutations in melanoma patients: implications for molecular testing in clinical practice. British Journal of Cancer 108(10), 2164-71.

Hwa, C., Price, L. S., Belitskaya-Levy, I., Ma, M. W., Shapiro, R. L., Berman, R. S., Kamino, H., Darvishian, F., Osman, I., and Stein, J. A. (2012). Single versus multiple primary melanomas: old questions and new answers. Cancer 118(17), 4184-92.

Jemal, A., Saraiya, M., Patel, P., Cherala, S. S., Barnholtz-Sloan, J., Kim, J., Wiggins, C. L., and Wingo, P. A. (2011). Recent trends in cutaneous melanoma incidence and death rates in the United States, 1992-2006. Journal of the American Academy of Dermatology 65(5 Suppl 1), S17-25 e1-3.

Kang, C., Qaqish, B., Monaco, J., Sheridan, S. L., and Cai, J. (2013). Kappa statistic for clustered dichotomous responses from physicians and patients. Statistics in Medicine 32(21), 3700-19.

Krauthammer, M., Kong, Y., Ha, B. H., Evans, P., Bacchiocchi, A., Mccusker, J. P., Cheng, E., Davis, M. J., Goh, G., Choi, M., et al. (2012). Exome sequencing identifies recurrent somatic RAC1 mutations in melanoma. Nature Genetics 44(9), 1006-1014.

Landis, J. R., and Koch, G. G. (1977). The measurement of observer agreement for categorical data. Biometrics 33(1), 159-74.

Liu, W., Kelly, J. W., Trivett, M., Murray, W. K., Dowling, J. P., Wolfe, R., Mason, G., Magee, J., Angel, C., Dobrovic, A., et al. (2007). Distinct clinical and pathological features are associated with the BRAF(T1799A(V600E)) mutation in primary melanoma. Journal of Investigative Dermatology 127(4), 900-5.

Long, G. V., Hauschild, A., Santinami, M., Atkinson, V., Mandalà, M., Chiarion-Sileni, V., Larkin, J., Nyakas, M., Dutriaux, C., Haydon, A., et al. (2017). Adjuvant Dabrafenib plus Trametinib in Stage III BRAF-Mutated Melanoma. New England Journal of Medicine 377, 1813-1823.

Long, G. V., Menzies, A. M., Nagrial, A. M., Haydu, L. E., Hamilton, A. L., Mann, G. J., Hughes, T. M., Thompson, J. F., Scolyer, R. A., and Kefford, R. F. (2011). Prognostic and clinicopathologic associations of oncogenic BRAF in metastatic melanoma. Journal of Clinical Oncology 29(10), 1239-46. 
Luke, J. J., Flaherty, K. T., Ribas, A., and Long, G. V. (2017). Targeted agents and immunotherapies: optimizing outcomes in melanoma. Nature Reviews Clinical Oncology 14(8), 463-482.

Maldonado, J. L., Fridlyand, J., Patel, H., Jain, A. N., Busam, K., Kageshita, T., Ono, T., Albertson, D. G., Pinkel, D., and Bastian, B. C. (2003). Determinants of BRAF mutations in primary melanomas. Journal of the National Cancer Institute 95(24), 1878-90.

Manganoni, A. M., Farisoglio, C., Tucci, G., Facchetti, F., and Calzavara Pinton, P. G. (2007). The importance of self-examination in the earliest diagnosis of multiple primary cutaneous melanomas: a report of 47 cases. Journal of the European Academy of Dermatology and Venereology 21(10), 1333-6.

Mar, V. J., Wong, S. Q., Li, J., Scolyer, R. A., Mclean, C., Papenfuss, A. T., Tothill, R. W., Kakavand, H., Mann, G. J., Thompson, J. F., et al. (2013). BRAF/NRAS wild-type melanomas have a high mutation load correlating with histologic and molecular signatures of UV damage. Clinical Cancer Research 19(17), 4589-98.

Mccaul, K. A., Fritschi, L., Baade, P., and Coory, M. (2008). The incidence of second primary invasive melanoma in Queensland, 1982-2003. Cancer Causes \& Control 19(5), 451-8.

Mcmeniman, E., De'ambrosis, K., and De'ambrosis, B. (2010). Risk factors in a cohort of patients with multiple primary melanoma. Australasian Journal of Dermatology 51(4), 254-7.

Menzies, A. M., Haydu, L. E., Visintin, L., Carlino, M. S., Howle, J. R., Thompson, J. F., Kefford, R. F., Scolyer, R. A., and Long, G. V. (2012). Distinguishing clinicopathologic features of patients with V600E and V600K BRAF-mutant metastatic melanoma. Clinical Cancer Research 18(12), 3242-9.

Menzies, A. M., Lum, T., Wilmott, J. S., Hyman, J., Kefford, R. F., Thompson, J. F., O'toole, S., Long, G. V., and Scolyer, R. A. (2014). Intrapatient homogeneity of BRAFV600E expression in melanoma. American Journal of Surgical Pathology 38(3), 377-82.

Moloney, F. J., Guitera, P., Coates, E., and Et Al. (2014). Detection of primary melanoma in individuals at extreme high risk: A prospective 5-year follow-up study. JAMA Dermatology 150(8), 819-827.

Moore, M. M., Geller, A. C., Warton, E. M., Schwalbe, J., and Asgari, M. M. (2015). Multiple primary melanomas among 16,570 patients with melanoma diagnosed at Kaiser Permanente Northern California, 1996 to 2011. Journal of the American Academy of Dermatology 73(4), $630-6$.

Moscarella, E., Rabinovitz, H., Puig, S., Zalaudek, I., Oliviero, M. C., Brown, L., Alarcon, I., Malvehy, J., Longo, C., Formisano, D., et al. (2013). Multiple primary melanomas: do they look the same? British Journal of Dermatology 168(6), 1267-72.

Murali, R., Goumas, C., Kricker, A., From, L., Busam, K. J., Begg, C. B., Dwyer, T., Gruber, S. B., Kanetsky, P. A., Orlow, I., et al. (2012). Clinicopathologic features of incident and 
subsequent tumors in patients with multiple primary cutaneous melanomas. Annals of Surgical Oncology 19(3), 1024-33.

Nardin, C., Puzenat, E., Pretet, J. L., Algros, M. P., Doussot, A., Puyraveau, M., Mougin, C., and Aubin, F. (2015). BRAF mutation screening in melanoma: is sentinel lymph node reliable? Melanoma Research 25(4), 328-34.

Omholt, K., Platz, A., Kanter, L., Ringborg, U., and Hansson, J. (2003). NRAS and BRAF mutations arise early during melanoma pathogenesis and are preserved throughout tumor progression. Clinical Cancer Research 9(17), 6483-8.

Pizzichetta, M. A., Talamini, R., Stanganelli, I., Puddu, P., Bono, R., Argenziano, G., Veronesi, A., Trevisan, G., Rabinovitz, H., and Soyer, H. P. (2004). Amelanotic/hypomelanotic melanoma: clinical and dermoscopic features. British Journal of Dermatology 150(6), 1117-24.

Poynter, J. N., Elder, J. T., Fullen, D. R., Nair, R. P., Soengas, M. S., Johnson, T. M., Redman, B., Thomas, N. E., and Gruber, S. B. (2006). BRAF and NRAS mutations in melanoma and melanocytic nevi. Melanoma Research 16(4), 267-73.

Riveiro-Falkenbach, E., Villanueva, C. A., Garrido, M. C., Ruano, Y., Garcia-Martin, R. M., Godoy, E., Ortiz-Romero, P. L., Rios-Martin, J. J., Santos-Briz, A., and Rodriguez-Peralto, J. L. (2015). Intra- and Inter-Tumoral Homogeneity of BRAF(V600E) Mutations in Melanoma Tumors. Journal of Investigative Dermatology 135(12), 3078-3085.

Robert, C., Karaszewska, B., Schachter, J., Rutkowski, P., Mackiewicz, A., Stroiakovski, D., Lichinitser, M., Dummer, R., Grange, F., Mortier, L., et al. (2015). Improved Overall Survival in Melanoma with Combined Dabrafenib and Trametinib. New England Journal of Medicine 372, 30-39.

Saint-Jean, M., Quereux, G., Nguyen, J. M., Peuvrel, L., Brocard, A., Vallee, A., Knol, A. C., Khammari, A., Denis, M. G., and Dreno, B. (2014). Is a single BRAF wild-type test sufficient to exclude melanoma patients from vemurafenib therapy? Journal of Investigative Dermatology 134(5), 1468-1470.

Salerni, G., Carrera, C., Lovatto, L., Puig-Butille, J. A., Badenas, C., Plana, E., Puig, S., and Malvehy, J. (2012). Benefits of total body photography and digital dermoscopy ("Two-step method of digital follow-up") in the early diagnosis of melanoma in high risk patients. Journal of the American Academy of Dermatology 67(1), e17-e27.

Satzger, I., Marks, L., Kerick, M., Klages, S., Berking, C., Herbst, R., Volker, B., Schacht, V., Timmermann, B., and Gutzmer, R. (2015). Allele frequencies of BRAFV600 mutations in primary melanomas and matched metastases and their relevance for BRAF inhibitor therapy in metastatic melanoma. Oncotarget 6(35), 37895-905.

Savoia, P., Osella-Abate, S., Deboli, T., Marenco, F., Stroppiana, E., Novelli, M., Fierro, M. T., and Bernengo, M. G. (2012). Clinical and prognostic reports from 270 patients with multiple 
primary melanomas: a 34-year single-institution study. Journal of the European Academy of Dermatology and Venereology 26(7), 882-8.

Schuurman, M. S., De Waal, A. C., Thijs, E. J. M., Van Rossum, M. M., Kiemeney, L. a. L. M., and Aben, K. K. H. (2016). Risk factors for second primary melanoma among Dutch melanoma patients. British Journal of Dermatology 174(4): 971-978.

Shain, A. H., Yeh, I., Kovalyshyn, I., Sriharan, A., Talevich, E., Gagnon, A., Dummer, R., North, J., Pincus, L., Ruben, B., et al. (2015). The Genetic Evolution of Melanoma from Precursor Lesions. New England Journal of Medicine 373, 1926-36.

Siskind, V., Hughes, M. C., Palmer, J. M., Symmons, J. M., Aitken, J. F., Martin, N. G., Hayward, N. K., and Whiteman, D. C. (2011). Nevi, family history, and fair skin increase the risk of second primary melanoma. Journal of Investigative Dermatology 131(2), 461-7.

Sosman , J. A., Kim, K. B., Schuchter , L., Gonzalez , R., Pavlick , A. C., Weber , J. S., Mcarthur , G. A., Hutson, T. E., Moschos , S. J., Flaherty , K. T., et al. (2012). Survival in BRAF V600Mutant Advanced Melanoma Treated with Vemurafenib. New England Journal of Medicine 366, $707-714$.

Stam-Posthuma, J. J., Van Duinen, C., Scheffer, E., Vink, J., and Bergman, W. (2001). Multiple primary melanomas. Journal of the American Academy of Dermatology 44(1), 22-7.

Titus-Ernstoff, L., Perry, A. E., Spencer, S. K., Gibson, J., Ding, J., Cole, B., and Ernstoff, M. S. (2006). Multiple primary melanoma: two-year results from a population-based study. Archives of Dermatology 142(4), 433-8.

Vecchiato, A., Pasquali, S., Menin, C., Montesco, M. C., Alaibac, M., Mocellin, S., Campana, L. G., Nitti, D., and Rossi, C. R. (2014). Histopathological characteristics of subsequent melanomas in patients with multiple primary melanomas. Journal of the European Academy of Dermatology \& Venereology 28(1), 58-64.

Vernali, S., Waxweiler, W. T., Dillon, P. M., Kanetsky, P. A., Orlow, I., Luo, L., Busam, K. J., Kricker, A., Armstrong, B. K., Anton-Culver, H., et al. (2017). Association of Incident Amelanotic Melanoma With Phenotypic Characteristics, MC1R Status, and Prior Amelanotic Melanoma. JAMA Dermatol 153(10), 1026-1031.

Viera, A. J., and Garrett, J. M. (2005). Understanding interobserver agreement: the kappa statistic. Family Medicine 37(5), 360-3.

Viros, A., Fridlyand, J., Bauer, J., Lasithiotakis, K., Garbe, C., Pinkel, D., and Bastian, B. C. (2008). Improving melanoma classification by integrating genetic and morphologic features. PLoS Medicine 5(6), e120.

Watts, C. G., Cust, A. E., Menzies, S. W., Mann, G. J., and Morton, R. L. (2017). Cost-Effectiveness of Skin Surveillance Through a Specialized Clinic for Patients at High Risk of Melanoma. Journal of Clinical Oncology 35(1), 63-71. 
Wong, S. Q., Li, J., Tan, A. Y., Vedururu, R., Pang, J. M., Do, H., Ellul, J., Doig, K., Bell, A., Macarthur, G. A., et al. (2014). Sequence artefacts in a prospective series of formalin-fixed tumours tested for mutations in hotspot regions by massively parallel sequencing. BMC Medical Genomics 7, 23.

Youlden, D. R., Baade, P. D., Aitken, J. F., Green, A. C., and Khosrotehrani, K. (2017). Prognostic importance of a second invasive primary melanoma according to tumour stage. British Journal of Dermatology. doi: 10.1111/bjd.15863. [Epub ahead of print].

Youlden, D. R., Baade, P. D., Soyer, H. P., Youl, P. H., Kimlin, M. G., Aitken, J. F., Green, A. C., and Khosrotehrani, K. (2016). Ten-Year Survival after Multiple Invasive Melanomas Is Worse than after a Single Melanoma: a Population-Based Study. Journal of Investigative Dermatology 136(11), 2270-2276.

Youlden, D. R., Youl, P. H., Soyer, H. P., Aitken, J. F., and Baade, P. D. (2014). Distribution of subsequent primary invasive melanomas following a first primary invasive or in situ melanoma Queensland, Australia, 1982-2010. JAMA Dermatology 150(5), 526-34.

Table 1. Patient characteristics among patients with single and multiple primary melanomas.

\begin{tabular}{|c|c|c|c|}
\hline Clinical characteristic* & $\begin{array}{c}\text { SPM } \\
\text { patients } \\
\text { n }(\%)\end{array}$ & $\begin{array}{c}\text { MPM } \\
\text { patients } \\
\text { n }(\%)\end{array}$ & $p$ value \\
\hline Total number of patients & 1484 & 154 & \\
\hline Sex & & & \\
\hline Male & $857(57.8)$ & $101(65.6)$ & \multirow{2}{*}{0.06} \\
\hline Female & $627(42.3)$ & $53(34.4)$ & \\
\hline \multicolumn{4}{|l|}{$\begin{array}{l}\text { Age at first melanoma } \\
\text { diagnosis }\end{array}$} \\
\hline$<60$ years & $784(52.9)$ & $122(30.1)$ & \multirow{2}{*}{$<0.001$} \\
\hline$\geq 60$ years & $699(47.1)$ & $284(69.9)$ & \\
\hline \multicolumn{4}{|l|}{ Family history of melanoma } \\
\hline No & $1133(80.2)$ & $121(79.6)$ & \multirow{2}{*}{0.9} \\
\hline Yes & $279(19.8)$ & $31(20.4)$ & \\
\hline \multicolumn{4}{|l|}{ History of NMSC } \\
\hline No & $1032(72.2)$ & $82(55.0)$ & \multirow{2}{*}{$<0.001$} \\
\hline Yes & $397(27.8)$ & $67(45.0)$ & \\
\hline \multicolumn{4}{|l|}{ Skin Phototype } \\
\hline I & $462(32.3)$ & $48(31.4)$ & \multirow{3}{*}{0.6} \\
\hline II & $606(42.4)$ & $71(46.4)$ & \\
\hline III-V & $362(25.3)$ & $34(22.2)$ & \\
\hline \multicolumn{4}{|l|}{ Hair colour } \\
\hline Red & $130(9.2)$ & $15(11.5)$ & 0.7 \\
\hline
\end{tabular}




\begin{tabular}{|l|cc|}
\hline Blonde & $287(20.2)$ & $27(20.8)$ \\
\hline Brown & $931(65.6)$ & $79(60.8)$ \\
\hline Black & $71(5.0)$ & $9(6.9)$ \\
\hline Eye colour & & \\
\hline Blue & $783(56.0)$ & $84(65.1)$ \\
\hline Green & $169(12.1)$ & $16(12.4)$ \\
\hline Hazel & $212(15.2)$ & $13(10.1)$ \\
\hline Brown & $234(16.7)$ & $16(12.4)$ \\
\hline
\end{tabular}

SPM: single primary melanoma, MPM: multiple primary melanoma, NMSC: non-melanoma skin cancer

*Some variables have small amounts of missing data

Table 2. Tumour characteristics of single and multiple primary melanomas.

\begin{tabular}{|c|c|ccc|}
\hline & & \multicolumn{3}{|c|}{ Multiple primary melanoma patients } \\
\hline Tumour characteristics & $\begin{array}{c}\text { Single } \\
\text { primary } \\
\text { melanoma } \\
\text { n (\%) }\end{array}$ & $\begin{array}{c}\text { First } \\
\text { primary } \\
\text { melanoma } \\
\text { n (\%) }\end{array}$ & $\begin{array}{c}\text { Second } \\
\text { primary } \\
\text { melanoma } \\
\text { n (\%) }\end{array}$ & $\begin{array}{c}\text { Third } \\
\text { primary } \\
\text { melanoma } \\
\text { n (\%) }\end{array}$ \\
\hline Total number of melanomas ${ }^{\mathrm{a}}$ & 1,484 & 154 & 154 & 56 \\
\hline Anatomical location & & & & \\
\hline Head \& neck & $352(23.9)$ & $32(20.9)$ & $44(28.6)$ & $13(23.2)$ \\
\hline Trunk & $469(31.8)$ & $63(41.2)$ & $51(33.1)$ & $22(39.3)$ \\
\hline Upper extremity & $360(24.4)$ & $33(21.6)$ & $27(17.5)$ & $12(21.4)$ \\
\hline Lower extremity & $294(19.9)$ & $25(16.3)$ & $32(20.8)$ & $9(16.1)$ \\
\hline Breslow thickness & & & & \\
\hline In situ & $81(5.5)$ & $24(17.0)$ & $55(36.7)$ & $20(37.7)$ \\
\hline$<1.0 \mathrm{~mm}$ & $435(29.5)$ & $48(34.0)$ & $54(36.0)$ & $25(47.2)$ \\
\hline $1.0-4.0$ mm & $721(49.0)$ & $51(36.2)$ & $31(20.7)$ & $8(15.1)$ \\
\hline$>4.0 \mathrm{~mm}$ & $236(16.0)$ & $18(12.8)$ & $10(6.7)$ & $0(0)$ \\
\hline
\end{tabular}




\begin{tabular}{|c|c|c|c|c|}
\hline \multicolumn{5}{|l|}{ Histologic subtype } \\
\hline SSM & $882(59.4)$ & $76(56.3)$ & $81(55.1)$ & $43(65.4)$ \\
\hline NM & $367(24.7)$ & $29(21.5)$ & $16(10.9)$ & $3(5.8)$ \\
\hline LMM & $131(8.8)$ & $21(15.6)$ & $39(26.5)$ & $15(28.9)$ \\
\hline *Other & $104(7.0)$ & $9(6.7)$ & $11(7.5)$ & $0(0)$ \\
\hline \multicolumn{5}{|l|}{ Mitotic rate $\left(n / \mathbf{m m}^{2}\right)$} \\
\hline$<5$ & $993(67.5)$ & $110(79.7)$ & $136(90.1)$ & $51(94.4)$ \\
\hline $5-9$ & $263(17.9)$ & $19(13.8)$ & $7(4.6)$ & $0(0)$ \\
\hline$\geq 10$ & $215(14.6)$ & $9(6.5)$ & $8(5.3)$ & $3(5.6)$ \\
\hline \multicolumn{5}{|l|}{ Ulceration } \\
\hline Yes & $381(26.4)$ & 27 (19.9) & $13(8.6)$ & $2(3.7)$ \\
\hline No & $1062(73.6)$ & $109(80.2)$ & $138(91.4)$ & $52(96.3)$ \\
\hline \multicolumn{5}{|l|}{ Regression } \\
\hline Yes & $322(24.3)$ & $36(25.7)$ & $37(24.5)$ & $13(23.6)$ \\
\hline No & $1001(75.7)$ & $104(74.3)$ & $114(75.5)$ & $42(76.4)$ \\
\hline \multicolumn{5}{|c|}{ Tumour-infiltrating lymphocytes } \\
\hline Yes & $582(49.2)$ & $45(32.9)$ & $38(25.2)$ & $9(16.7)$ \\
\hline No & $600(50.8)$ & $92(67.2)$ & $113(74.8)$ & $45(83.3)$ \\
\hline \multicolumn{5}{|l|}{ Pigmentation } \\
\hline Hypomelanotic/amelanotic & $83(5.7)$ & $5(3.4)$ & $6(4.1)$ & $1(2.1)$ \\
\hline Pigmented & $1384(93.3)$ & $144(96.6)$ & $140(95.9)$ & 47 (97.9) \\
\hline
\end{tabular}

SSM: superficial spreading melanoma, NM: nodular melanoma, LMM: lentigo maligna melanoma.

* 'Other' represents acral lentiginous melanoma, desmoplastic melanoma and other less common tumour subtypes including naevoid, balloon cell, spindle cell and Spitzoid melanoma.

${ }^{\text {a }}$ Some variables have small amounts of missing data

Table 3. BRAF mutation status concordance among first and successive primary cutaneous melanomas in patients with multiple primary melanomas.

\begin{tabular}{|c|c|c|c|c|}
\hline $\begin{array}{l}\text { No. of matched } \\
\text { primary } \\
\text { melanomas } \\
\text { with } B R A F \\
\text { mutation } \\
\text { testing }\end{array}$ & $\begin{array}{l}\text { No. of patients } \\
\text { with matched } \\
\text { Samples with } \\
\text { BRAF } \\
\text { mutation } \\
\text { testing }\end{array}$ & $\begin{array}{l}\text { No. patients } \\
\text { with all } \\
\text { BRAF WT } \\
\text { tumours } \\
\text { (concordant) }\end{array}$ & $\begin{array}{l}\text { No. patients } \\
\text { with all } B R A F \\
\text { mutant } \\
\text { tumours } \\
\text { (concordant) }\end{array}$ & $\begin{array}{l}\text { Patients with } \\
\text { both } B R A F \text { WT } \\
\text { and } B R A F \\
\text { mutant tumours } \\
\text { (discordant) }\end{array}$ \\
\hline $\mathbf{0}$ & 21 & & & \\
\hline 1 & 69 & & & \\
\hline$\overline{2}$ & 48 & 33 & 2 & 13 \\
\hline 3 & 14 & 9 & 1 & 4 \\
\hline 5 & 1 & 1 & 0 & 0 \\
\hline 9 & 1 & 0 & 0 & 1 \\
\hline
\end{tabular}


Table 4. NRAS mutation status concordance among first and successive primary cutaneous melanomas in patients with multiple primary melanomas.

\begin{tabular}{|c|c|c|c|c|}
\hline $\begin{array}{l}\text { No. of matched } \\
\text { primary } \\
\text { melanomas } \\
\text { with } N R A S \\
\text { mutation } \\
\text { testing }\end{array}$ & $\begin{array}{l}\text { No. of patients } \\
\text { with matched } \\
\text { samples with } \\
\text { NRAS } \\
\text { mutation } \\
\text { testing }\end{array}$ & $\begin{array}{l}\text { No. patients } \\
\text { with all } \\
\text { NRAS WT } \\
\text { tumours } \\
\text { (concordant) }\end{array}$ & $\begin{array}{l}\text { No. patients } \\
\text { with all } N R A S \\
\text { mutant } \\
\text { tumours } \\
\text { (concordant) }\end{array}$ & $\begin{array}{l}\text { Patients with } \\
\text { both } N R A S \text { WT } \\
\text { and } N R A S \\
\text { mutant tumours } \\
\text { (discordant) }\end{array}$ \\
\hline 0 & 30 & & & \\
\hline 1 & 66 & & & \\
\hline 2 & 42 & 35 & 1 & 6 \\
\hline 3 & 14 & 10 & 0 & 4 \\
\hline 5 & & 0 & 0 & 1 \\
\hline 9 & 1 & 1 & 0 & 0 \\
\hline
\end{tabular}

Figure 1. Patients and tissue samples included in the study.

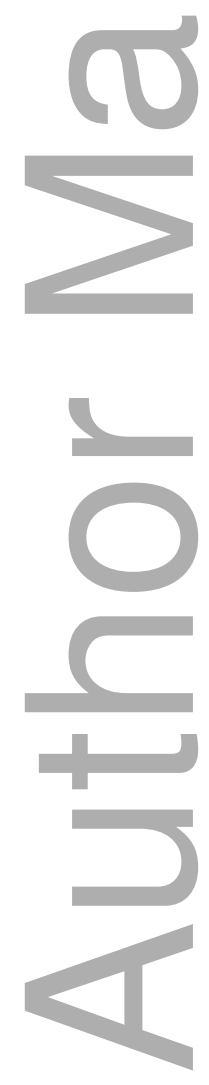




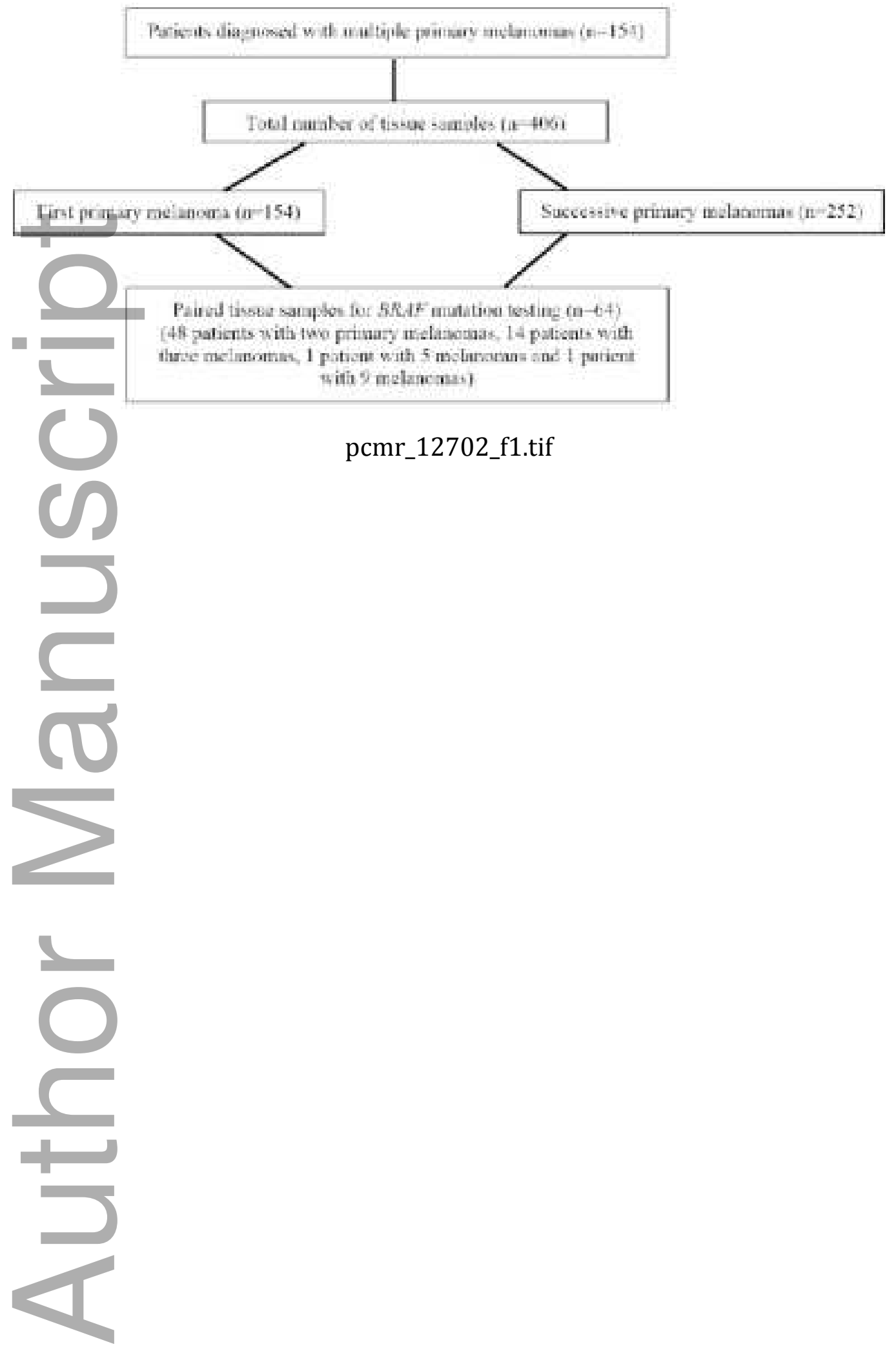

This article is protected by copyright. All rights reserved 


\section{University Library}

\section{- M M N E R VA A gateway to Melbourne's research publications}

Minerva Access is the Institutional Repository of The University of Melbourne

Author/s:

Adler, NR;McLean, CA;Wolfe, R;Kelly, JW;McArthur, GA;Haydon, A;Tra, T;Cummings, N;Mar, VJ

Title:

Concordance of somatic mutational profile in multiple primary melanomas

Date:

2018-09-01

Citation:

Adler, N. R., McLean, C. A., Wolfe, R., Kelly, J. W., McArthur, G. A., Haydon, A., Tra, T., Cummings, N. \& Mar, V. J. (2018). Concordance of somatic mutational profile in multiple primary melanomas. PIGMENT CELL \& MELANOMA RESEARCH, 31 (5), pp.592-603. https://doi.org/10.1111/pcmr.12702.

Persistent Link:

http://hdl.handle.net/11343/283880 